\title{
EDUCAÇÃO INTEGRAL, ENSINO INTEGRAL E TEMPO NO PENSAMENTO DE RUI BARBOSA ${ }^{1}$
}

\author{
Nailda Marinho da Costa Bonato \\ nbonato@yahoo.com.br \\ Lígia Martha Coimbra da Costa Coelho \\ ligiamartha@alternex.com.br \\ Janaína Specht da Silva Menezes \\ janainamenezes@hotmail.com
}

PPGEdu/UNIRIO

\section{RESUMO}

A partir da Reforma Leôncio de Carvalho, Rui Barbosa, relator da Comissão de Instrução Pública, elaborou seus "Pareceres sobre a Reforma do Ensino Primário, Secundário e Superior". O que nos interessa, nessa série de pareceres, são os referentes ao ensino primário. Ao tratar de "Métodos e programa escolar", o jurista defende o "princípio do ensino integral" (p.57) e a necessidade de "instrução integral" (p.60). Levando em conta nosso campo de investigação, perguntamos: O que Rui Barbosa entendia por ensino integral? Qual sua concepção acerca do mesmo? Relacionava ensino integral com tempo integral na escola primária? O estudo que propomos se inscreve como parte da pesquisa institucional "Tempo integral e educação integral no Ensino Fundamental", em andamento, financiada pelo Observatório da Educação, no âmbito da CAPES/INEP e que apresenta, como um de seus objetivos "Identificar e historicizar concepções e práticas de educação integral em tempo integral, ao final do século XIX e ao longo do século XX". Para compor nossa análise, trabalharemos com os textos da Reforma e dos Pareceres e com referencial teórico acerca das categorias educação integral e tempo integral, visando contextualizar as reflexões de Rui Barbosa em torno da questão.

Palavras-chave: Educação Integral; Reforma Leôncio de Carvalho; Rui Barbosa

\section{FULL-TIME EDUCATION IN RUI BARBOSA'S THOUGHT}

\begin{abstract}
From Leôncio de Carvalho Reform, Rui Barbosa, the rapporteur of the Public Education Commission, did his "Pareceres sobre a Reforma do Ensino Primário, Secundário e Superior". What we are interested in these reports is all information about Elementary Education. On dealing with "Methods and school programs", the jurist defends "the principle of full-time education" (p.57) and the need of "full-time instruction" (p.60). Taking into consideration our research field, we ask: What was Barbosa's opinion about full-time education? What was his conception of this theme? Did he relate full-time education to full time in elementary school? The study we propose is part of the institutional research in progress entitled "Full time and full-time education in Elementary Education" and is funded by Observatório da Educação in the sphere of CAPES/INEP. One of its objectives is to "identify throughout history the conceptions and practices of full-time Education in full time at the end of the $19^{\text {th }}$ century and over the $20^{\text {th }}$ century". In order to carry out our analysis, we will work with the texts of the Reform, the texts of the reports on the Reform and bibliographic reference to full-time education and full time aiming to contextualize Barbosa's reflections around the topic.
\end{abstract}

Keywords: Full-time Education; Leôncio de Carvalho Reform; Rui Barbosa 


\title{
Introdução
}

A história da Educação Brasileira relata que os alentados Pareceres sobre a Reforma do Ensino Primário, Secundário e Superior, de autoria de Rui Barbosa ${ }^{2}$, foram elaborados na vigência do Decreto n. ${ }^{\circ} 7.247$, de 19 de abril de 1879 , expedido pelo ministro do Império, o Conselheiro professor Carlos Leôncio de Carvalho, conforme podemos constatar no volume X, tomo IV, da edição de 1947, da "Reforma do Ensino Primário e várias instituições complementares da instrução pública". No apêndice III, intitulado "Projetos Rodolfo Dantas", há uma nota de rodapé esclarecendo que

Os pareceres foram provocados - como esclarecem inicialmente, e como já ficou estudado no Vol. IX, tomo I, destas Obras Completas, - pela reforma do Conselheiro Carlos Leoncio de Carvalho, dec. 7.247, de 19 de abril de 1879. (N. Rev.). (FCRB, 1947, p.215-6)

O referido Parecer sobre A Reforma do Ensino Primário e Várias Instituições Complementares da Instrução Pública é datado de 12 de setembro de 1882, "dia em que os Anais do Parlamento consignam sua apresentação". (Ibid., prefácio, p.XI, volume X, Tomo I) $)^{3}$ e, de acordo com Saviani (2007) "o projeto nem chegou a ser discutido no Parlamento" (p.164) ou seja, não teve andamento. Porém, sua leitura é bastante significativa para pensarmos a educação do seu tempo. À época, Rui Barbosa era, então, relator da Comissão de Instrução Pública ${ }^{4}$ e, no campo educacional,

\begin{abstract}
Os dados encontrados nos Pareceres [...] são significativos da situação do ensino primário. Eles apontam que naquele ano o município da Corte possuía 96 escolas públicas primárias; dessas, 54 eram destinadas ao sexo masculino e 42 ao "segundo sexo". O número de matriculados do sexo masculino nas escolas públicas era de 3.042, e nas escolas particulares de 2.592; para o sexo feminino, era de 3.087 matrículas nas escolas públicas e 2.939 nas particulares. O número total de matriculados nas escolas públicas era de 6.129 e, nas particulares, de 5.531, perfazendo um total de 11.660, para uma população de 312.554 pessoas livres (Barbosa, 1947, p. 18-24). O que Rui Barbosa tenta mostrar é que neste item, a educação, [no municipio neutro] está atrasada em relação à média do país, reforçando a necessidade de uma reforma educacional. (BONATO, 2003)
\end{abstract}

Em que pese o significativo e denso olhar do jurista para a totalidade da Educação Brasileira, à época em questão, o que nos interessa, na série de pareceres que compõem a obra citada, são aqueles referente ao ensino primário, mais especificamente, o que constitui o Volume X das Obras Completas de Rui Barbosa editadas pela Fundação Casa de Rui Barbosa. Nesse volume, estruturado em três tomos, o eminente jurista trata, no Tomo II, dos "Métodos e Programa Escolar", defendendo o "princípio do ensino integral" (p. 57) e a necessidade de "instrução integral" (p. 60). O Tomo III discute o tempo na escola.

No Núcleo de Estudos-Tempos, Espaços e Educação Integral ${ }^{5}$, vimos discutindo as temáticas a que nos referimos - educação integral, ensino integral e tempo na escola -, tanto em relação às concepções e práticas que as materializam, quanto aos contornos históricos que as constituem, no panorama da Educação brasileira. Assim, levando em conta esse nosso campo de investigação, perguntamos: O que Rui Barbosa entendia por ensino integral: o mesmo que educação integral? Relacionava ensino integral com tempo integral na escola primária? Quais práticas educacionais ele defendia, no sentido de concretizar a educação integral, por meio do ensino integral? 
O ensaio que ora apresentamos visa discutir estas questões, uma vez que nossos estudos acerca da temática da educação integral vêm, há algum tempo, como já destacamos, aprofundando-se também na abordagem histórica. O trabalho inscreve-se, ainda, como parte da pesquisa institucional "Tempo integral e educação integral no Ensino Fundamental”, finalizada no ano de 2010, financiada pelo Observatório da Educação, no âmbito do convênio CAPES/INEP e que apresentava, como um de seus objetivos, "identificar e historicizar concepções e práticas de educação integral em tempo integral, ao final do século XIX e ao longo do século XX".

Em termos metodológicos, o ensaio parte de pesquisa bibliográfica e documental para compor a análise dos textos. Trabalhamos com fontes primárias como a Reforma Leôncio de Carvalho e o texto denominado Reforma do Ensino Primário e Várias Instituições Complementares da Instrução Pública, mais conhecido como os Pareceres de Rui Barbosa. Fazem parte ainda de nosso referencial teórico, artigos e obras que discutem as categorias educação integral e tempo escolar/integral, visando contextualizar as reflexões do jurista em torno dessa temática.

$\mathrm{O}$ ensaio estrutura-se em três seções. Em primeiro lugar, contextualizamos o momento mesmo de elaboração dos Pareceres de Rui Barbosa, ou seja, o movimento de apresentação da Reforma Leôncio de Carvalho e os motivos que geraram a reflexão do jurista.

Em uma segunda seção, debruçamo-nos sobre o recorte que move este estudo, já citado anteriormente - o Tomo II que, ao tratar dos "Métodos e Programa Escolar", aborda o ensino integral, abarcando, ainda, o Tomo III, que discute o tempo na escola. Concluindo o estudo, refletimos sobre a importância das argumentações do jurista na constituição histórica da educação integral e do(s) tempo(s) escolar(es) no Brasil, desde a época do Império.

E já iniciando o debate, perguntamos: Por que Rui Barbosa se lança na tarefa de apresentar uma série de Pareceres sobre a educação, no país? Acreditamos que, para se entender o pensamento de Rui Barbosa, nessa série de pareceres que apresentou à Câmara de Deputados, se faz necessário conhecer o teor da Reforma Leôncio de Carvalho e, também, os motivos que a geraram.

\section{Educação no Império: A Reforma Leôncio de Carvalho e seus desdobramentos}

A sociedade brasileira do século XIX, tradicionalmente de base agrária escravocrata, mais notadamente nas últimas décadas daquele século, estava sendo abalada por mudanças em sua estrutura econômica e social, passando de rural-agrícola para urbano-comercial. Liberais e cientificistas estabelecem pontos comuns em seus programas de ação como, por exemplo,

[...] abolição dos privilégios aristocráticos, separação da Igreja do Estado, instituição do casamento e registro civil, secularização dos cemitérios, abolição da escravidão, libertação da mulher para, através da instrução, desempenhar seu papel de esposa e mãe, e a crença na educação, chave dos problemas fundamentais do país. (RIBEIRO, 2003, p.65).

Ribeiro vai afirmar que o consumo de "novas idéias" - influenciadas pelas idéias européias e norte-americanas, onde a economia capitalista se encontrava em expansão, fica explícito no manifesto liberal de 1868 , considerado como "o início de um amplo movimento que vai agitar o final do Império e o início da República”. (Ribeiro, 2003, p. 64) onde a crença no liberalismo e no cientificismo são os pilares de sustentação para 
elevar o Brasil à condição de nação moderna, tendo em vista os modelos importados dos países considerados civilizados.

A abolição do tráfico negreiro, em 1850, e a lei do Ventre Livre, em 1871, são marcos significativos, na segunda metade do século XIX, que trazem problemas para o Estado Imperial, relativos à alocação dessa população livre num país que se queria moderno e civilizado. 1879 foi um ano em que as primeiras crianças nascidas livres de mãe escrava completariam 8 anos, podendo essas crianças serem entregues ao Estado, mas também a associações particulares de instrução. Nesse sentido, Fonseca afirma que

[...] imediatamente após a aprovação da lei [do ventre livre], as propostas para constituição de associações e a instrução começavam a ser apresentadas e bem acolhidas pelo Ministério da Agricultura, que via nessas associações a possibilidade de recolher as crianças nascidas livres de mãe escrava, pois o governo não possuía uma estrutura capaz de recebê-las e muito menos estava disposto a criá-las sob sua inteira direção e responsabilidade. Assim, o caminho para realização de parcerias com particulares revelava-se como o mais conveniente a ser formado, aliás como sugeria a própria lei. (FONSECA, 2002, p.67)

As idéias renovadoras chegaram e circularam no Brasil de várias formas. A presença do imperador D. Pedro II e seus conselheiros nas Exposições Universais realizadas a partir de 1851 , fez com que se tomasse contato, principalmente nas duas últimas décadas do regime imperial, com o que era considerado moderno nos países avançados. Essas Exposições eram verdadeiras "vitrines do progresso" (Barros, 1997), reunindo a produção internacional. Os próprios espaços construídos para abrigar as exposições representavam essa modernidade e progresso da sociedade industrial, que se constituía no mundo ocidental europeu e norte-americano. Por exemplo, na Exposição Internacional de Higiene e Educação, realizada em Londres (1884), o Brasil enviou participantes e palestrantes, entre eles o conselheiro do império Leôncio de Carvalho, que dissertou sobre educação e trabalho. Paralelamente às Exposições Universais, aconteciam congressos especializados em diversas áreas, sendo possível aos conselheiros do imperador entrarem em contato com as idéias pedagógicas daquelas nações modernas. Com esse olhar sobre países europeus e da América do Norte, a partir da segunda metade do século XIX, começam a ocorrer mudanças na educação brasileira, influenciadas pelas reformas educacionais ocorridas naqueles países. (Bonato, 2003).

Dessa forma, ao "mesmo tempo em que participavam do Estado, favorecendo a sua manutenção, esses [sujeitos sociais e políticos] preconizavam transformações nas estruturas sociais, na perspectiva de que a educação equivalia a progresso." (Bastos, 2005, p.130). Eram os casos de Leôncio de Carvalho e Rui Barbosa, que faziam parte da estrutura que compunha o regime imperial. Influenciados pelas idéias do mundo moderno, debatiam, já com ventos republicanos, a necessidade de mudanças na organização e estrutura escolar e, conseqüentemente, nos métodos de ensino.

Nesta direção renovadora, o exemplo americano ganha visibilidade através dos relatórios de Hippeau e Buisson, ambos franceses. Nos relatórios, abordam temas como jardins de infância, formação de professores, disciplinas escolares, ensino particular e de ordens religiosas, co-educação, educação feminina, lições de coisas ou exercícios do pensamento. (Gondra, 2004 e Bastos, 2002). Ao escrever os Pareceres, onde faz um meticuloso levantamento do ensino nos países mais avançados, Rui Barbosa procurou fundamentar o seu pensamento principalmente com leituras de autores estrangeiros, entre 
eles Buisson e reafirma lições de coisas como método necessário à transformação do ensino nas escolas brasileiras.

Na perspectiva de modernização do país, a instituição escolar vai aparecer como um dos espaços privilegiados para se atingir esse objetivo. Calorosos debates apontavam suas deficiências "no sentido de imprimir nas escolas o viés mais liberal em implantação nos Estados Unidos, de defesa das idéias de ensino e de consciência, bem como as novidades pedagógicas que circulavam no exterior" (ARANHAranha, 2006, p. 225). Para essa autora, no campo da educação, é o modelo americano que ganha força a partir da década de 1860.

Na década de 1870, os diversos profissionais que atuavam na escola ou nos serviços de instrução, políticos, médicos, engenheiros, afirmavam a precariedade dos espaços escolares. No Brasil, a partir de 1873, foram realizadas conferências pedagógicas, onde temas como as inovações do mundo moderno e o fracasso do método mútuo ${ }^{6}$ (monitorial lancasteriano), moral e higiene, eram discutidos. Essas Conferências "faziam parte de um movimento internacional, no qual a elite intelectual brasileira procurava integrar-se e vivenciá-lo na sua realidade social.” (BASTOS, 2005, p.130), como vimos em parágrafo anterior.

Nesse movimento de introdução das idéias liberais no seio de uma sociedade ainda bastante conservadora, Leôncio de Carvalho, "o inovador de ensino mais audacioso e radical do período do Império" no dizer de Fernando de Azevedo (1963, p.598), apresenta sua Reforma Educacional, no ano de 1879, composta de um longo texto, contendo "174 itens agrupados em 29 artigos, eventualmente desdobrados em parágrafos e incisos, porém não ordenados em títulos ou capítulos." (Saviani, 2007, p.136). De cunho liberal, esse documento legal estabelecia, entre outras, normas para o ensino primário, secundário e superior da educação brasileira e instituía a liberdade de ensino primário e secundário na Corte e do ensino superior no país.

Em relação ao ato de educar, entendia que todos os que se considerassem capacitados para ensinar poderiam fazê-lo, independentemente de serem professores, expondo suas idéias e adotando os métodos que melhor lhes conviessem, garantindo assim o espaço para iniciativas particulares no campo da educação, uma tendência que se acentuava, face a ausência do Estado ${ }^{7}$.

Instituída em meio às determinações da Constituição de 1824, a Reforma Leôncio de Carvalho foi ao encontro daquela Carta constitucional ao assegurar, dentre outros aspectos, a "instrução primária e gratuita a todos os cidadãos" (art.179, inciso XXXII). Tendo como um de seus princípios a co-educação dos sexos, a Reforma também determinava a freqüência obrigatória para a faixa etária de 7 a 14 anos, cujos jovens deveriam frequientar todas as disciplinas que constituíam o programa das escolas primárias $\left(\right.$ art. $2^{\circ}$ ). Salvo exceções ${ }^{8}$, estavam sujeitos a multas os "pais, mãis, tutores ou protectores" que deixassem de matricular na escola primária de $1^{\circ}$ grau pública os jovens sob sua responsabilidade integrantes daquela faixa etária $\left(\operatorname{art} .2^{\circ}, \S^{\circ}\right)$.

A análise das disciplinas 9 que integravam o currículo das escolas primárias de $1^{\circ} \mathrm{e}$ $2^{\circ}$ graus do município da Corte revela a obrigatoriedade daquelas voltadas para a formação integral do homem, dentro dos limites conceituais e operacionais vigentes à época. Nesse sentido, podemos dizer que, a fim de possibilitar uma educação integral, o decreto, em relação ao tempo de escola determinava, ainda, no seu artigo $4^{\circ}$, que:

$\S 2^{\circ}$ As escolas, tanto do $1 .^{\circ}$ como do $2 .^{\circ}$ gráo, funccionarão, durante o verão (de $1 .^{\circ}$ de Outubro a 31 de Março) das 81,2 horas da manhã ás 2 1,2 da tarde, e durante o inverno (de $1 .^{\circ}$ de Abril a 30 de Setembro) das 9 ás 3 horas da tarde, interrompendo-se os trabalhos do meio dia á 1 hora 
para recreio dos alumnos, pratica manual de officios e exercícios de gymmastica, sob as vistas do Professor ou adjunto. Para os alunos menores de 10 anos deverão os trabalhos escolares terminar ao meio dia.

Em síntese, a análise da reforma Leôncio de Carvalho nos permite inferir que há uma associação entre educação integral e ampliação do tempo escolar, no caso, 6 (seis) horas diárias para os jovens com dez anos ou mais. Afora isto, ao determinar, nos diferentes distritos do mesmo município, a criação de pequenas bibliotecas e museus escolares $\left(\operatorname{art.} 7^{\circ}\right)$, embora de forma embrionária, traz para a reflexão aspectos pertinentes a ampliação não só do tempo, mas, também, dos espaços educacionais, enquanto aspectos relacionados (porém, não-necessários) à configuração de uma educação integral à época.

Também conhecida como "A reforma do ensino livre", a Reforma Leôncio de Carvalho pregava a liberdade de ensino; de frequiência e de credo religioso, buscando ir ao encontro as mudanças que se operavam na sociedade brasileira e conseqüentemente ao pensamento educacional vigente ao final da década de 1870. Em relação à liberdade de ensino e de metodologias, esse documento legal enfatizava:

A organização de colégios com propostas divergentes, como, por exemplo, os de tendência positivista, que, valorizando as ciências, pudessem superar o ensino acadêmico e humanista da tradição colonial. Teve a iniciativa de sugerir a adoção do método intuitivo ou de lições de coisas (ARANHA ranha, 2006, p.225). (Grifo nosso).

No caso do credo religioso, preconizava: "Os alumnos catholicos não são obrigados a frequentar a aula de instrucção religiosa" (Art. $4^{\circ}$, parágrafo $1^{\circ}$ ). Por último, partindo da determinação de que "É completamente livre o ensino primário e secundário no município da Corte e o superior em todo o Império, salvo a inspecção necessária para garantir as condições de moralidade e hygiene" (art. $1^{\circ}$ ), a liberdade de ensino fazia-se associar, também, à necessidade de o Estado incentivar a ampliação do número de estabelecimentos de ensino no país, num momento em que: (1) a taxa de escolarização correspondia, em 1886, a apenas $1,8 \%$ da população (incluindo negros e índios) (Almeida apud Rezende Pinto, 2000) ${ }^{10}$ e que (2) o Brasil estava buscando produzir as condições de modernização exigidas pelo capital.

Em síntese, no dizer de Maria Lúcia Arruda Aranha:

A reforma de Leôncio de Carvalho, embora radical, esteve em vigor por pouco tempo, mas a discussão sobre a interferência ou não do Estado continuou acesa. Por exemplo, Rui Barbosa atribuía ao Estado a obrigação de tomar para si os cuidados com a educação, porque, entre outras coisas, as escolas particulares se orientavam pelas leis do mercado. Essas discussões repercutiram de maneira mais efetiva nos primeiros anos da República." (ARANHA, 1996, p.225)

Essa reforma foi, assim, amplamente discutida por Rui Barbosa, em seus Pareceres. No entanto aqui, como já dissemos, o que nos interessa é o que trata do ensino primário intitulado Reforma do Ensino Primário e Várias Instituições Complementares da Instrução Pública e, mais especificamente, o que esta obra discute acerca do ensino integral e do tempo na escola.Nesse sentido, o que nos dizem esses Pareceres, com relação a essas duas possibilidades, na educação? 


\section{Os Pareceres de Rui Barbosa, o ensino integral e o tempo na escola}

Tendo em vista a reforma Leôncio de Carvalho, em 13 de abril de 1882, Rui Barbosa - considerado "talvez a maior cabeça do parlamento atual"11, nos dizeres de Belmiro de Almeida -, apresenta, como relator da Comissão de Instrução Pública na Câmara, o Parecer e o Projeto de Reforma do Ensino Primário, Secundário e Superior, publicados no Rio de Janeiro pela Tipografia Nacional, no mesmo ano.

Como afirmamos na Introdução, o que nos interessa é a série de pareceres acerca da Reforma do Ensino Primário e Várias Instituições Complementares da Instrução Pública, estruturada em quatro tomos que compõem o volume $\mathrm{X}$ das Obras completas de Rui Barbosa. publicadas pela Fundação Casa de Rui Barbosa. Embora apresentados ao plenário da Câmara de Deputados em 12 de setembro de 1882, só foram impressos pela Tipografia Nacional em 1883, revistos por Rui Barbosa. (FCRB, 1995, p.52-3). O "Parecer sobre o Ensino Secundário e Superior" foi reeditado em 1942 (vol. IX, Tomo I) e o "Parecer sobre o Ensino Primário", em 1947 (Vol. X - Tomos I a IV), conforme Eraldo Tinoco Melo, Secretário de Educação do estado da Bahia, na apresentação do Tomo I desse Parecer.

O tomo II do Parecer sobre o ensino primário dedica-se a dois pontos importantes em relação à educação formal - a liberdade de ensino e os métodos e programa escolar. Neste último item, o autor reflete sobre o tema que o nomeia e, depois, subdivide-o em doze partes, em que vai discutindo cada uma das disciplinas que, segundo sua perspectiva, deveriam compor o programa escolar do ensino primário brasileiro. No entanto, interessanos exatamente essa reflexão inicial. Nela, expõe sua concepção de educação, bem como a(s) prática(s) necessária(s) à sua consecução. Rui Barbosa defendia a ampliação do programa escolar, justificada pelo princípio da educação integral, princípio instituído sob a égide da mesma trindade pedagógica defendida por médicos higienistas: educação física, intelectual e moral.

Conforme Gondra (2004) no Brasil dos Oitocentos, mais especificamente na segunda metade do século XIX, a concepção higienista marcou presença, contribuindo para o projeto de intervenção científica na educação. Um grupo composto por médicos formados pela Faculdade de Medicina do Rio de Janeiro considerava que a educação ideal para a formação de um novo homem brasileiro deveria contemplar as três dimensões humanas - a física, a intelectual e a moral -, entendida como educação integral dessa formação. Citado por Gondra, a reflexão do médico higienista Armonde, em dissertação defendida no ano de 1874, é exemplo dessa concepção:

[...] A educação, todos sabem, comprehende três ramos: educação physica, moral e intellectual. Tão intima são as relações que entre si guarda esta tríplice ramificação, que muitas questões não podem ser classificadas nesse ramo, por se ligarem igualmente aos outros. Tratando de uma questão de educação physica, por exemplo, nada mais natural do que passar-se insensivelmente para uma questão de educação moral e intelectual. Uma das dificuldades do nosso ponto está, pois, precisamente nessa intima correlação, nessa quase inseparabilidade das questões. (Dr. Armonde, 1874, apud GONDRA ondra 2004, p. 275)

Assim, era necessária uma renovação pedagógica e, para isso, a implantação de um método de ensino que fosse capaz de efetivá-la. Nesse sentido, o debate estava posto entre Leôncio de Carvalho e Rui Barbosa, duas figuras envolvidas com a modernização do sistema educacional brasileiro e do país. 
Com a fluência verbal que o caracterizava, o jurista inicia aquele item a que aludimos em parágrafo anterior - métodos e programa escolar -, já prenunciando sua postura favorável à total inversão do método utilizado para ensinar nas escolas brasileiras:

Cumpre renovar o método, orgânica, substancial, absolutamente, nas nossas escolas. Ou antes, cumpre criar o método; porquanto o que existe entre nós, usurpou um nome, que só por antífrase lhe assentaria: não é o método de ensinar; é, pelo contrário, o método de inhabilitar para aprender (1947, p.33).

Durante laudas, o autor exemplifica o que denominou como "método de inabilitar para aprender", utilizando argumentos oriundos dos campos da saúde e da pedagogia. No campo da saúde, a fisiologia humana é destacada por meio de uma bem elaborada descrição sobre a capacidade do cérebro humano - "o cérebro desenvolve-se pelo exercício que lhe é peculiar [...] Um órgão que não se exerce, solicita do cérebro menos atividade do que um órgão em exercício" (ps.70-7). Em relação à prática pedagógica, Rui Barbosa afirma o uso quase exclusivo da memória, da pedagogia da repetição, da pergunta-resposta, em uma crítica contundente aos métodos de ensino que Paulo Freire, anos e anos após, denominaria de pedagogia bancária (1979).

Visando exemplificar sua argumentação, Rui Barbosa cita as visitas realizadas a escolas municipais - "que são das menos mal organizadas nesta capital" (p.38) - e, notadamente, a uma dessas instituições. Nessa situação de campo, o mestre examinava alunos e "o objeto das perguntas, o modo de interrogar, a natureza das respostas, tudo qualifica(va) o estado lastimoso do ensino" (p. 39). Assim, chega o autor à conclusão de que, no aluno, só pode sobreviver "o enjôo do estudo, o horror à escola" (p. 41).

Concomitante a essa exaustiva argumentação, Rui Barbosa vai apresentando o que denomina de "método renovado". É interessante atentar para algumas das características que marcam a sua natureza:

Quando a reforma enuncia a aspiração de aditar, com estudos omitidos até hoje neste país, o programa da escola, não faltam à ignorância os conhecidos lugares comuns, para declamar contra a inconveniência dos "programas sobrecarregados". Todo o programa de ensino irracionalmente concebido e irracionalmente praticado, não educa, não instrue, não esclarece (p.51).

Uma das condições cardeais da reforma escolar, portanto, está em fazer da intuição a base de todo o método, de todo o ensino, de toda a educação humana (p.53).

O princípio do ensino integral, entrevisto pelo alto engenho de Rabelais e formulado pela filosofia positiva, é o norte, a que deve tender a reorganização da escola. [...] A melhor instrução consiste numa recapitulação, tão completa quanto ser possa, do progresso que a humanidade tem efetuado por entre o curso dos séculos (p.57). (Grifo nosso)

A esta virtual influência da educação integral [...] derivou do sentimento profundo da igualdade e do direito, que a todo homem assiste, sejam quais forem as circunstâncias em que o acaso o fez nascer, de desenvolver, da maneira mais completa possível, todas as suas faculdades físicas e intelectuais (p.58). (Grifo nosso) 
Aos quatro trechos citados anteriormente e retirados dos Pareceres, muitos outros poderíamos adicionar. No entanto e de certa forma, aqui está representado o pensamento de Rui Barbosa acerca do que denomina de "método renovado" e "educação integral". Em outras palavras, a mudança na educação formal, para o autor, se daria por meio de uma outra concepção, consubstanciada em uma outra prática na escola, que levaria em conta o princípio da educação/ensino integral. E em que consistiria essa perspectiva da pedagogia moderna, tão intensamente defendida pelo renomado jurista?

Pelo teor dos trechos citados, inferimos que, para Rui Barbosa, educação integral significa ampliação da formação do aluno no ensino primário "numa recapitulação tão completa quanto ser possa, do progresso que a humanidade tem efetuado por entre o curso dos séculos". Significa assim trabalhar, na escola, "da maneira mais completa possível, todas as suas faculdades físicas e intelectuais"; em outras palavras, significa ensinar as disciplinas das ciências físicas e naturais, a língua materna, a matemática, a história e a geografia, mais a educação física, a música, o desenho, o canto, os "rudimentos de economia política", cultura moral, cultura cívica ou seja, todas as que, após a alentada reflexão inicial, o autor vai analisar, ao longo do já citado tomo II e que constituem as habilidades físicas, cognitivas e estéticas que completam, no sujeito, o seu SER humano.

Em síntese, podemos dizer que Rui Barbosa refere-se à educação integral a partir do que compreende como ensino integral. A leitura do tomo II nos possibilita afirmar que, para o autor, essa educação integral materializa-se por meio do ensino integral "recapitulação do progresso que a humanidade tem efetuado" - trabalhado de forma integrada e a partir da intuição - "base de todo o método, de todo o ensino, de toda a educação humana".

De acordo com Lourenço Filho ${ }^{12}$, o jurista defendia, em seus Pareceres, uma educação que não se apoiasse:

[...] apenas no racional e no lógico, mas no poder criador do espírito como entidade livre. Por isso a metodologia a que deveria tender seria integral, como integral é a sua pedagogia. Nesse sentido, o seu pensamento se sintetiza nestas poucas palavras: "Toda reforma sincera, em matéria escolar, depende de três modificações cardeais no organismo do ensino, desde o primeiro momento de sua função educadora: a introdução na escola da cultura física, da cultura cientifica e da cultura artística." (LOURENÇO FILHO ourenço Filho, 2001, p.53). Grifos nossos.

Nessa Nova Pedagogia, aos mestres caberia, em sua missão de educar, estimular o aluno a discernir os fenômenos naturais e sociais, a estudar as realidades como ideal de educação integral, contendo tanto a educação do corpo, através dos exercícios ginásticos e dos preceitos higiênicos ${ }^{13}$, quanto a educação intelectual e manual, com a aprendizagem de ofícios. (MARTINEZ artinez, 1998).

De acordo com Souza, tal princípio - o da educação integral -, fora formulado e difundido, no período do Império, a partir da obra de Spencer, Educação intellectual, moral e physica, publicada em 1861. Esse principio se coadunava com as aspirações da sociedade moderna:

O apelo de Spencer á correspondência entre lei da evolução biológica (lei do desenvolvimento orgânico) e o processo social possibilitou a naturalização da evolução da sociedade e a compreensão da ciência como 
o conhecimento mais relevante, o conhecimento útil com a aplicação no trabalho na arte e na vida diária. (SOUZA ouza, 2000, p.14)

Essa concepção, em que corpo e espírito são indissociáveis, era compartilhada por Rui Barbosa, o que pode ser verificado em seus Pareceres. De acordo ainda com Souza, a educação integral:

[...] converteu-se no primeiro fundamento pedagógico sistemático para a seleção dos conteúdos para a escola primária. A definição de uma nova cultura escolar para o povo encontrou justificações filosóficas e pedagógicas para amparar um projeto de fundo político e social." (Souza, 2000, p.14 )

Para se atingir essa educação integral, em que a indissociabilidade entre aspectos físicos, intelectuais e estéticos era o fundamento político-epistemológico, o "programa sobrecarregado" apresentado pelo jurista era, segundo ele, o mínimo que se poderia pensar em trabalhar, no ensino primário. E como isto se daria, em termos práticos? Por meio de uma "visão positiva, racional" que, inferimos, também se alicerça no método intuitivo, na "lição de coisas", que possibilitaria à criança "formar a ciência [...] não extraindo-a dos livros, mas da contemplação do céu e da terra; isto é, ensinando-os a perceberem e a escrutarem diretamente as coisas" (p.202).

Segundo Rui Barbosa, a reforma do ensino primário dar-se-ia por meio de um programa ampliado em sua raiz, porque mais fidedigno aos avanços da civilização humana. Essa ampliação seria constituída por disciplinas que não existiam enquanto tal, na pedagogia tradicional, formando as bases da educação integral. No entanto, para o autor, de nada adiantaria pensar em uma educação integral que correspondesse a uma prática escolar baseada naquela pedagogia, bem como nos mesmos métodos livrescos, de reprodução. Assim, o jurista defende, concomitantemente, um método baseado na intuição, na observação, no concreto - fundamentos do pensar racional e positivo. Esse método baseado na intuição fundava-se na lição de coisas, forma de transformar aquela educação em ensino integral.

Em síntese, e tentando responder as questões formuladas na Introdução deste estudo, inferimos que educação integral e ensino integral, para Rui Barbosa são conceitos próximos, quando o autor pensa em um programa mais denso, mais completo. Esta "recapitulação", contudo, se dará por meio da utilização cotidiana da "lição de coisas", o que constitui o ensino integral na prática.

As Lições de coisas, também conhecidas como método intuitivo seriam consideradas por Rui Barbosa como o método de ensino mais adequado para as aspirações sobre o ensino primário. Por considerar importante a divulgação do método intuitivo entre os professores, Rui Barbosa traduziu as "Primeiras Lições de Coisas", do norte-americano Norman Allyson Calkins, método discutido e propagado em seus Pareceres. A primeira edição data de 1861, sendo reformulado e ampliado em 1870, traduzido por Rui Barbosa em 1881 e publicado no Brasil em 1886. (SAVIANI aviani, 2007, p.139). Lacombe, ao referenciar o trabalho de tradução das "Lições das Coisas" de Calkins, realizado pelo eminente jurista, diz "que, durante muitos anos vai-se tornar-se obra clássica para nosso magistério primário. Deste trabalho disse Lourenço Filho que é uma das maiores contribuições para a formação de uma mentalidade educativa no Brasil." (LACOMBEacombe Apud. VALLE alle, 1997, p.50) 
Os defensores do método intuitivo argumentavam a necessidade de o espaço da sala de aula permitir que as diversas classes pudessem realizar as lições de coisas. A ênfase no método estava:

[...] no reconhecimento de que os sentidos são a porta para todo o conhecimento. Ao contrário da tradição, que valoriza o ensino discursivo, que atua por raciocínio lógico e, portanto, é abstrato, busca-se começar a instrução primária educando a sensibilidade, pela qual percebemos cores, formas, sons, luz etc. É esta que prepara e antecipa a intuição intelectual, quando então percebemos as relações (de igualdade, causalidade etc.) entre as coisas. Ou seja, rejeitando a educação livresca, a criança deveria aprender a ler o mundo visível, pela observação e percepção das relações entre os fenômenos. (ARANHA ranha, 2006, p.232)

Ainda conforme Aranha, "embora a expressão lições de coisas servisse para indicar o método intuitivo aplicado em todas as disciplinas, com frequiência ela designava o ensino elementar das ciências da natureza, isto é, restringia-se a uma das disciplinas do currículo". (Ibid.). Neste sentido Rui Barbosa, se elogia a introdução das Lições de coisas na escola popular, por outro lado faz a critica de como essa proposta é concretizada, uma vez que compartimentalizada em uma única disciplina, ou seja, sem fomentar uma prática realmente inovadora no ensino, em geral. Em suas palavras:

Bem procedeu, portanto, o decreto de 19 de abril, introduzindo na escola popular as lições de coisas. Desacertou, porém, indigitando-as como capítulo singular, distinto, independente entre as matérias do programa. Nada contribuiria mais para inutilizar de todo essa inovação, para a levar a uma degenerescência imediata, do que uma especialização tal, que parte da compreensão imperfeita da natureza do ensino. A lição de coisas não é um assunto especial no plano de estudos: é um método de estudo; não se circunscreve a uma secção do programa: abrange o programa inteiro; não ocupa, na classe, um ligar separado, como a leitura, a geografia, o cálculo, ou as ciências naturais: é o processo geral, a que se devem subordinar todas as disciplinas professadas na instrução elementar. (1947, p.215)

Tendo como fonte as Atas e Pareceres do Congresso da Instrução do Rio de Janeiro, de 1884, Valdemarin (2004) nos informa que Leôncio de Carvalho, neste Congresso, rebate as críticas de Rui Barbosa a sua Reforma, principalmente no que se refere a Lições de coisas. Diz o Conselheiro que Rui Barbosa, ao confundir as Lições de Coisas com método intuitivo, não atenta para a diferença entre eles:

[...] .a lição de cousas é uma parte do método intuitivo; é preciso que este se aplique aos exercícios da inteligência e aos atos de raciocínio. A intuição sensível só serve quando prepara para a intuição intelectual. (VALDEMARIN, 2004, p.3)

Para Valdemarin (2006), o manual Primeiras lições de coisas, contendo prescrições metodológicas para o ensino, dividido em lições, exercícios e atividades, é um marco significativo da tentativa de se implantar, no ensino brasileiro, o método intuitivo, que remonta à década de 1880. À época, esse método didático é inovador, 
[...] consoante com a renovação pedagógica em curso na Europa e nos Estados Unidos da América, cujos efeitos poderiam ser irradiados para toda a sociedade, implementando as transformações sociais, políticas e econômicas almejadas nas últimas décadas do Império. $\mathrm{O}$ discurso político e educacional produzido nessa época estabelece estreitos vínculos entre as propostas de inovação metodológica e a difusão do ideário liberal republicano, destacando-se a utilização das lições de coisas ou método intuitivo como estratégia de intervenção na sala de aula, lócus especifico da instrução e da mudança das práticas pedagógicas, adequando a escola ao projeto político modernizador. (VALDEMARIN, 2006, p.90)

Ou De acordo com Souza (2008) Em 1881, no relatório ministerial, Rodolfo de Souza Dantas, amigo de Rui Barbosa, em relação à situação da instrução popular, defende o que denominou de Nova Pedagogia. Para o ministro, era preciso mudar o ensino até então baseado nas fórmulas gramaticais, no catecismo e nas tabuadas que eram decorados. (SOUZA, 2008) A modalidade de transmissão de conhecimentos preconizada por ele seria através do método intuitivo. Para o Ministro do Império, o ensino deveria fornecer ao menino a capacidade de ver, de sentir, de esquadrinhar, de executar, de inventar. Esse método racional fundamentava-se em uma concepção filosófica e científica pela qual a aquisição de conhecimentos advinha dos sentidos e da observação. A racionalidade pedagógica articulava-se com os princípios de racionalização da produção e da vida social. (SOUZA, 2008). Tal método fora prescrito para as escolas brasileiras.

Vale ressaltar ainda que, como a "Lição de coisas" demandava passeios, visitas, entre outros, subentende-se que a reforma Leôncio de Carvalho de 1879, ao ampliar os espaços educacionais, já percebia a educação integral integrada ao território, visão que se aproxima do atual conceito de educação integral. Dentro dessa perspectiva, bastante próxima da "Pedagogia moderna", Rui Barbosa pergunta: "Caberá, porém, nos limites do possível, a aplicação do princípio da integralidade do ensino à escola primária?" (p.58).

Acreditamos que uma possível resposta a essa pergunta se localiza no tomo III de seus Pareceres. Essa obra, Rui Barbosa inicia com o item VIII - Organização Pedagógica - no qual encontramos, em primeiro lugar, a discussão sobre Emprego do tempo. Duração das lições. Nesse ponto, o jurista estabelece toda uma argumentação em torno do tempo na escola discutindo, desde o tempo dedicado a cada aula, quanto o tempo diário/semanal. E realiza essa tarefa apresentando a situação do tempo escolar em vários países europeus, dentre outros. Conta-nos, por exemplo, que "na Suécia, a duração das aulas é de 5 a 6 horas por dia e [...] se divide em dois períodos: manhã e tarde. A classe da manhã [...] compreende toda a educação mental. Às 2 horas começam os trabalhos da tarde: prendas feminis; ginástica; manejo de armas e exercícios militares" (p.4).

Continuando suas reflexões acerca do tempo, chega à realidade brasileira. Diz-nos, então, que "entre nós, no município da Corte, segundo o programa e horário vigentes, o dia escolar é dividido em dois tempos: um de três horas, pela manhã, no verão; outro de duas à tarde" (p.7), totalizando cinco horas de trabalho escolar consecutivo, o que o autor considera inadmissível. Essa avaliação, o jurista a faz enfatizando - novamente - os aspectos fisiológicos, ou seja, a questão não está presente na extensão do horário escolar, mas sim na importância de que, a cada aula, haja um intervalo que recompense o esforço desprendido pela criança. Em suas palavras, "a questão dos recreios, portanto, e da duração do trabalho escolar é do mais elevado alcance possível, quer em relação à higiene, quer no tocante ao aproveitamento real das classes que pretendemos educar" (p. 8): 
Juntamente com o método era imperiosa a reorganização do programa escolar. A esse respeito, Rui segue mais uma vez as idéias pedagógicas predominantes na época, isto é a ampliação do programa escolar justificada pelo principio da educação integral: educação física, intelectual e moral. (SOUZA, 2000, p.13)

Em síntese, a argumentação de Rui Barbosa no tocante ao tempo escolar reforça que "o estudo árduo e prolongado não é nocivo à saúde [...] a cultura não amadurece nem as letras se fecundam, senão à custa de aturado e laborioso esforço" (p.10). No entanto, há necessidade de que a criança espaireça e, para isso, enfim, ele arbitra que:

em vez de cortar a duração total das aulas diárias em duas sessões [...] reduziremos o dia escolar a uma sessão só, dividida em tempos de breve duração com recreios intermédios [...] o alvitre de uma sessão só consulta melhor os interesses de uma boa distribuição do trabalho na escola (Ibid.?p.13).

Se atentarmos bem para a solução encontrada por Rui Barbosa para a distribuição do tempo escolar, verificamos que à extensão de 5 horas e 45 minutos para o curso elementar (ensino primário) corresponde 1 hora e 45 minutos de recreio e 4 horas diárias de aulas - de "educação mental" e de outras atividades relacionadas naquele programa ao qual já nos referimos. Ora, partindo dos trechos aqui analisados, e retornando então à questão anterior - Caberá, porém, nos limites do possível, a aplicação do princípio da integralidade do ensino à escola primária? - bem como a uma das perguntas com que abrimos este estudo - Relacionava Rui Barbosa o ensino integral com tempo integral na escola primária? -, a que conclusão podemos chegar?

Nossas reflexões nos levam a inferir que, para o eminente jurista, o ensino integral era possível, na escola primária, a partir da integralidade dos conhecimentos (o que corresponde a uma educação integral), e ao método com que esses conhecimentos deveriam ser trabalhados (a lição de coisas). No entanto, essa integralidade dependia de um tempo ampliado, que levasse também em conta os recreios "revigorantes ao espírito". Além do mais, esse tempo escolar devia se concentrar em uma única sessão.

O jurista parece apontar para a necessidade da não fragmentação em turnos manhã e tarde -, o que, segundo Rui Barbosa, desvirtuaria a "unidade da sessão escolar". Em outras palavras, para ele o estudo deveria ser concentrado e integrado, de tal forma que os alunos entendessem todas as atividades trabalhadas ao longo do dia escolar como significativas para a sua educação - sem momentos específicos de "educação mental" e de "outras atividades".

No que tange à estrutura da escolarização que deveria ser oferecida aos alunos das classes populares, dentro do espírito de uma renovação pedagógica, Rui Barbosa vai advogar "uma escola primária obrigatória e laica com oito anos de duração dividida em três graus: o elementar e o médio, cada um com dois anos de duração, e o superior, com quatro anos", substituindo a escola de primeiras letras - que não atendia mais a realidade que se constitua, pela escola primária moderna, com um programa capaz de direcionar para o progresso do país. (Ibid, 2000, p.12)

Fechando esta seção, podemos dizer que nosso estudo dos Pareceres de Rui Barbosa, no que dizem respeito à educação integral, ensino integral e tempo na escola, nos apresentou um pensamento vigoroso acerca dessas categorias de análise e da necessidade de sua implementação na Educação brasileira, à época. No entanto, nos perguntamos: Quais os desdobramentos desses Pareceres? Das propostas destacadas, quais as que 
vingaram, no panorama educacional brasileiro, naquele período? $\mathrm{E}$, ainda, qual a atualidade do pensamento de Rui Barbosa, hoje?

\section{Considerações finais}

No caso de Rui Barbosa, embora seus Pareceres não tenham sido aprovados, a influência desse pensamento permaneceu na Educação brasileira, como nos faz ver Lacombe quando, reeleito para o Senado afirma, em uma conferência proferida no Politeama Baiano, em 24 de maio de 1897, sobre a reforma proposta por Rui Barbosa: "Sua reforma é a primeira que visa a uma mudança social do país, encarando a escola como um elemento desta transformação." (LACOMBE apud VALLE, 1997, p.49). Para essa autora, Rui Barbosa visa "uma escola pública que [servisse] a 'regeneração' da pátria", entendendo ser o ensino um fator de desenvolvimento material e de progresso social, que, associado à questão da organização econômica e às cores de um nacionalismo inspirado nos discurso liberais radicais, irá se constituir como um "[...] fator de independência econômica nacional.” (Ibid. , p.51).

Ainda para a autora, "Rui Barbosa corporifica a influência americana claramente assumida e, nisto, faz jus, talvez, ao título de liberal" (p.46). Liberal, ou não, a série de Pareceres elaborados pelo autor representa, ainda hoje, um avanço em determinadas práticas escolares. Ou podemos dizer o contrário, quando constatamos sua defesa de, pelo menos, cinco horas e meia de trabalho escolar, em sessão única, constituída por atividades que levem em conta as variadas dimensões humanas?

Se fizermos um rápido retrospecto pelas questões que dizem respeito à ampliação do tempo escolar e à educação integral na Educação Brasileira, verificaremos que, na primeira metade do século XX, também Anísio Teixeira vem a público defender que a escola primária "visando, acima de tudo à formação de hábitos de trabalho, de convivência social, de reflexão intelectual, de gosto e de consciência, não pode limitar as suas atividades a menos que o dia completo" (p.79), buscando aquela ampliação do tempo e, também, um ensino mais completo, consubstanciado em parâmetros que não somente os que dizem respeito às habilidades cognitivas e intelectuais.

Dando um imenso passo em direção ao século XXI, verificamos que, contemporaneamente, várias experiências de ampliação da jornada escolar alicerçadas em uma formação mais completa vêm se espalhando pelo país afora, sendo talvez a mais significativa - em termos de abrangência territorial - a que foi criada em 2007, dentro do Plano de Desenvolvimento da Educação (PDE): o Programa Mais Educação e que defende atividades socioeducativas acontecendo em outros espaços, para além da escola.

Estes exemplos ratificam nosso pensamento de que, para além dos motivos que levaram Rui Barbosa à elaboração de seus Pareceres sobre a reforma de ensino proposta por Leôncio de Carvalho, a questão da educação/ensino integral emerge, de tempos em tempos na Educação Brasileira, como reflexão e prática possível, tendo em vista a hoje propagada necessidade de se oferecer uma escola de tempo integral visando uma educação integral para os alunos das classes populares.

\section{Referências}

ARANHA, Maria Lúcia de Arruda. História da educação e da pedagogia: geral e Brasil. $3^{\mathrm{a}}$ ed. rev. e ampl. São Paulo: Moderna, 2006.

AZEVEDO, Fernando. A cultura brasileira: introdução ao estudo da cultura no Brasil. São Paulo: Edições Melhoramentos, 1963. 
BARBOSA, Rui. Reforma do ensino primário e várias instituições complementares da instrução pública. Rio de Janeiro: Fundação Casa de Rui Barbosa, v.X, Tomos I, II e III, 1947. (Coleção Obras Completas de Rui Barbosa)

BARROS, Armando Martins de. Da pedagogia da imagem às práticas do olhar: uma busca de caminhos analíticos. Niterói. (Tese de Doutorado em Educação). Programa de Pós-Graduação em Educação da Universidade Federal Fluminense, 1997, 2v..

BASTOS, Maria Helena Câmara. A educação como espetáculo. In STEPHANOU, Maria, BASTOS, Maria Helena Câmara (orgs.). Histórias e memórias da educação no Brasil. Petrópolis, RJ: Vozes. v.II: século XIX, 2005.

.Leituras da ilustração brasileira: Célestin Hippeau (1803-1883). Revista de história da educação, jan.jun., n.3, 2002.

BONATO, Nailda Marinho da Costa. Co-educação no Brasil do século XIX ou o investimento na criança escolar. Idéias \& argumentos. Revista semestral de divulgação cientifica do Centro Unisal. São Paulo: Centro Universitário Salesiano - Universidade de Americana. Ano 2, n. 2 e 3, pp. 122-141, $1^{\circ}$ sem./2001.

A escola profissional para o sexo feminino através da imagem fotográfica. Campinas, SP: Unicamp, 2003. (Tese de Doutorado em Educação)

Nailda Marinho da Costa. Vozes de professores: a revista O ENSINO PRIMÁRIO (1884-1885). In. Anais do VI Congresso Brasileiro de História da Educação. Vitória: SBHE; UFES, de 16 a 19 de maio de 2011.

BRASIL. Decreto $n^{\circ}$ 7.247, de 19 de abril de 1879. Reforma do ensino primário e secundário no Município da Corte e o superior em todo o Império. Disponível em:

http://www2camara.gov.br/legislacao/publicacoes/doimperio. Acessado em: 25 jul. 2008.

CENTRO DE REFERÊNCIA da Educação Pública da Cidade do Rio de Janeiro. Guias das escolas de Anísio Teixeira. Rio de Janeiro: PCRJ/SME, 2006FONSECA, Marcus Vinicius. A educação dos negros: uma nova face do processo de abolição da escravidão no Brasil. Bragança Paulista: EDUSF, 2002 (Coleção Estudos CDAPH. Série Historiografia)

FONSECA, Marcus Vinícius. A educação dos negros: uma nova face do processo de abolição da escravidão no Brasil. Bragança Paulista: EDUSF, 2002. (Coleção Estudos CDAPH. Série Historiografia)

FREIRE, Paulo, Pedagogia do oprimido. São Paulo, Paz e Terra, 1979GHIRARDELLI Jr., Paulo. História da educação brasileira. São Paulo: Cortez, 2006.

GONDRA, JOSÉ Goncalves. Artes de civilizar: medicina, higiene e educação escolar na Corte Imperial. Rio de Janeiro: EdUERJ, 2004.

LOPES, Antônio Herculano. Um Antônio Conselheiro da razão. In. LUSTOSA, Isabel...[et al.]. Rio de Janeiro: Edicoes Casa de Rui Barbosa, 2000. pp. 71-124.

LOURENÇO FILHO, Manoel Bergstrom. A pedagogia de Rui Barbosa Ruy Lourenço Filho (Org.). $4^{\text {a }}$ edição, revisada e ampliada. Brasília - DF Inep/MEC. 2001

MARTINEZ, Alessandra F. Educar e Instruir: A Instrução Pública na Corte Imperial (1870 - 1889). Niterói. (Dissertação de Mestrado em Educação). Programa de PósGraduação em Educação da Universidade Federal Fluminense, 1998. 
REZENDE PINTO, José Marcelino. Os recursos para Educação no Brasil no contexto das finanças públicas. Brasília: Editora Plano, 2000.

RIBEIRO, Maria Luisa Santos. História da educação brasileira: a organização escolar. $18^{\text {a }}$ ed. rev. e ampl. Campinas, SP: Autores Associados, 2003. (Coleção memória da educação)

SAVIANI, Dermeval. História das idéias pedagógicas no Brasil. Campinas, SP: Autores Associados, 2007. (Coleção memória da educação).

SOUZA, Maria Zélia Maia de. Educar, trabalhar, civilizar no Asilo de Meninos

Desvalidos (1875-1894): caminhos possíveis. (Dissertação de Mestrado em Educação). Programa de Pós-Graduação em Educação - Mestrado da Rio de Janeiro: Universidade do Estado do Rio de Janeiro, 2008.

SOUZA, Rosa Fátima. Inovação educacional n século XIX: a construção do currículo da escola primária no Brasil. Cadernos Cedes. Educação, sociedade e cultura no século XIX: discursos e sociabilidades. Campinas, SP: Cedes, ano XIX, n.51, pp. 9-28, nov.2000.

TEIXEIRA, Anísio Spínola. Educação não é privilégio. 4 $4^{a}$ edição. São Paulo: Ed. Nacional, 1977. (atualidade pedagógica, v.130).

VALDEMANRIN, Vera Teresa. O método intuitivo: os sentidos como janelas e portas que se abrem para um mundo interpretativo. In. SAVIANI, Dermeval et. al. O legado educacional do século XIX. $2^{\mathrm{a}}$ ed. rev. e ampl. Campinas, SP: Autores Associados, 2006. pp.85-132. (Coleção educação contemporânea)

Estudando as Lições de Coisas. Análise dos fundamentos filosóficos do método de ensino intuitivo. Campinas, SP: Autores Associados, 2004. (Coleção educação contemporânea).

VALLE, Lílian do. A escola e a nação: as origens do projeto pedagógico brasileiro. São Paulo: Letras \& Letras, $1997 .{ }^{14}$

Notas:

\footnotetext{
${ }^{1}$ Este ensaio é fruto de investigação realizada no âmbito do projeto Educação integral e tempo integral no ensino fundamental, financiado pelo Observatório da Educação (CAPES/INEP) e foi apresentado no V CBHE - Congresso Brasileiro de História da Educação, realizado na cidade de Aracaju - SE, de 9 a 12 de novembro de 2008. Para o evento, foi aprovado o trabalho intitulado "Educação Integral no pensamento de Rui Barbosa", que para esta publicação foi revisto e ampliado.

${ }^{2}$ Os estudos sobre a atuação de Rui Barbosa no campo da educação são recentes e envolvem principalmente seus Pareceres. O jurista só se ocupou da educação num espaço de tempo muito curto, de 1881 a 1884 , motivado pela necessidade de modernização do país (Machado, 2002, Venancio Filho, 2007). Alguns autores datam esse período até 1886. Conforme a cronologia publicada no site da Fundação Casa de Rui Barbosa, a tradução e adaptação da obra didática "Lições de coisas", de Norman A. Calkins só foi publicada em 1886. Fonte: http://www.casaruibarbosa.gov.br . Acessado em 18 de fevereiro de 2011. Os periódicos datados de 31 de maio de 1884, ano I, sem número de identificação e de 15 de agosto de 1885, ano II, n. IV da revista $O$ Ensino Primário editada no município neutro da Corte imperial ${ }^{2}$, apontam para um Rui Barbosa atuante na Liga do Ensino e na revista dessa associação. A primeira página de cada exemplar impresso da revista "O Ensino Primário" indica tratar-se de uma "Revista mensal consagrada aos interesses do ensino e redigida por professores primários". De acordo com Alberto Venancio Filho no artigo intitulado "O liberalismo nos Pareceres de Educação de Rui Barbosa", publicado na revista Estudos Avançados, v.21, n.61, São Paulo, set./dez. 2007, no ano de 1864 (sic), provavelmente 1884, Rui Barbosa foi presidente da Liga do Ensino no Brasil e redator principal da Revista dessa associação, redigindo habitualmente o editorial. (Capturado em
} 
http://www.scielo.br/scielo.php?pid=S0103-4014200700030001\&script=sci_arttext . Acessado em 18 de fevereiro de 2011 (BONATO, 2011)

${ }^{3}$ Conforme o prefácio da obra citada, a folha de rosto do "Parecer menciona a data verdadeira do aparecimento do trabalho (1883)" (FCRB, 1947, prefácio, volume X, Tomo I)

${ }^{4}$ Em 8 de março de 1881, é nomeado membro do Conselho Superior de Instrução Pública. Fonte: http://www.casaruibarbosa.gov.br . Acessado em 18 de fevereiro de 2011.

${ }^{5}$ O Núcleo de Estudos -Tempos, Espaços e Educação Integral faz parte do Diretório de Grupos de Pesquisa do CNPq, desde 2007.

${ }^{6}$ Ensino mútuo ou monitorial, também conhecido como Lancaster. Método aplicado pelo anglicano Bell (1753-1832) e Lancaster (1778-1838), em suas respectivas escolas destinadas a crianças pobres e que tinha como objetivo instruir o maior número de alunos com o menor gasto possível. Neste método o professor não ensina todos os alunos, mas prepara apenas os melhores, que por sua vez atendem grupos de colegas. A divisa de Lancaster era: "Um só mestre para mil alunos." (Aranha, 2006, 203).

${ }^{7}$ No município da Corte, por exemplo, como realização de um Estado moderno, no campo da instrução pública, o Estado brasileiro só vai aparecer de forma mais consistente a partir das oito "Escolas do Imperador". Estas foram construídas com o produto da coleta de dinheiro a expensas oficiais e donativos do povo destinados a estátua do imperador D. Pedro II a ser erguida em sua homenagem, depois da guerra do Paraguai, com a vitória brasileira em 1870, se ele houvesse concordado. A negativa para a honraria fez com que o dinheiro fosse destinado para a construção de escolas no Rio de Janeiro (Azevedo, 1969; Primitivo, 1936). A instrução pública existia em prédios alugados, com pagamento de aluguéis elevados, o que provocava mudanças e despesas constantes. O governo imperial também subvencionava algumas escolas particulares. Entre 1870 e 1877 foram fundadas oito escolas destinadas à instrução primária de meninos e meninas no Município da Corte, sendo instaladas em prédios monumentais localizados em importantes espaços urbanos, com exceção da Escola da Freguesia da Gávea, de proporções menores. Embora construídas por iniciativa do Ministério do Império, contou com donativos de particulares. Só uma das oito escolas fora construída com verbas exclusiva do governo central. (SME/CREP, 2005, p.24 e 50).

${ }^{8}$ A obrigação de frequientar a escola primária pública deixava de existir nos casos em que os responsáveis provassem que os jovens: (1) freqüentavam escola particular, (2) assistiam aulas em suas próprias casas ou, (3) residiam a mais de $1,5 \mathrm{~km}$ (meninos) ou mais de $1,0 \mathrm{~km}$ (meninas) (art. $2^{\circ}$ ). Também se constituíam condições para a dispensa do ensino "a inabilidade physica ou moral e a indigência" (art. $2^{\circ}, \S 5^{\circ}$ ), estes últimos sujeitos ao auxílio do Conselho Diretor de Instrução Pública (art. $\left.2^{\circ}, \S 3^{\circ}\right)$.

${ }^{9}$ Disciplinas que integravam o ensino das escolas primárias de $1^{\circ}$ grau: "Instrucção moral, Instrucção religiosa, Leitura, Escripta, Noções de cousas, Noções essenciaes de grammatica, princípios elementares de arithmetica, Systema legal de pesos e medidas, Noções de historia e geographia do Brazil, Elementos de desenho linear, Rudimentos de musica (com exercício de solfejo e canto), Gymnastica, Costura simples (para as meninas)" (art. $4^{\circ}$ ). Já a escola primária de $2^{\circ}$ grau, além de aprofundar os conteúdos do $1^{\circ}$ grau, incluía as seguintes disciplinas: "Princípios elementares de algebra e geometria, Noções de physica, chimica e historia natural com explicação de suas principaes applicações á industria e aos usos da vida, Noções geraes dos deveres do homem e do cidadão, com explicação succinta da organização política do Império, Noções de lavoura e horticultura, Noções de economia social (para os meninos), Noções de economia doméstica (para as meninas), Pratica manual de oficcios (para os meninos) e Trabalhos de agulha (para as meninas).

${ }^{10}$ Quanto a estatística de escolarização no último quartel do século XIX, no Brasil, indicamos o item I "Estatística e situação do ensino popular", pp.7-83, do Tomo I, vol X das Obras Completas de Rui Barbosa

11 "Em 1882, Belmiro de Almeida fixava humoristicamente o traço do jovem político: talvez a maior cabeça do parlamento atual. O jogo de palavras entre a característica física e a intelectual faria a partir de então as delícias dos cartunistas. [...] Em carta ao senador Dantas, padrinho político de Rui Barbosa, os políticos goianos se referiam a este como um dos luzeiros mais brilhantes do parlamento nacional." (Lopes, 2000, pp.76-7). Tendo em vista a sapiência de Rui Barbosa, reconhecida por todos, a ele é creditada pelo imaginário popular certa prepotência. De acordo com Homero Senna (1994), correm a respeito do jurista "as histórias mais fantasiosas [...] . Está neste caso a lenda de que, chegando exilado à Inglaterra, teria colocado na porta de casa uma placa com os dizeres - "Ensina-se inglês aos ingleses". E aquela outra, de que, na Conferência de Haia, antes de responder a um aparte, indagara: "- Em que língua querem que eu fale?"(Senna, 1994, p.9 apud Bonato, 2011). 
12 Manoel Bergström Lourenço Filho, fundador da revista de Educação, na década de 1920 do século XX, professor de Escola Normal pública e particular, diretor do INEP em 1938, professor universitário, presidente da ABE de 1934 a 1938, escreveu diversas obras no campo da educação, como "Introdução ao Estudo da Escola Nova”, “Testes ABC”, "Educação Comparada”, “Organização e Administração Escolar”, “Têndencias da Educação Brasileira", "Psicologia Educaciona", que compõem a coleção "Obras completas de Lourenço Filho", organizada por Ruy Lourenço Filho. Para nossos estudos destacamos, como parte da coleção, a obra “A pedagogia de Rui Barbosa.", com primeira edição publicada em abril de 1954. Como o próprio titulo indica, nela o autor destaca o pensamento pedagógico do jurista.

${ }^{13}$ Saviani entende que a Reforma Leôncio de Carvalho “...traz à tona um elemento que ocupou lugar central no ideário pedagógico brasileiro no Segundo Império e ao longo da Primeira República: o higienismo. Esse tema ganhou força especialmente a partir da constituição da medicina como um campo disciplinar autônomo, o que ocorreu no século XIX.” (2007, p.137). Questão que por falta de espaço não iremos discutir, embora seja motivo de debate entre Leôncio de Carvalho e Rui Barbosa na perspectiva de se ofertar à escola popular uma educação integral, visando o sopro de modernização que passava o país.

Recebido em: $\quad 07 / 10 / 11$

Aprovado em: $\quad 31 / 01 / 12$ 